\title{
Modeling Laterally Loaded Single Piles Accounting for Nonlinear Soil-Pile Interactions
}

\author{
Maryam Mardfekri, ${ }^{1}$ Paolo Gardoni, ${ }^{2}$ and Jose M. Roesset ${ }^{1}$ \\ ${ }^{1}$ Zachry Department of Civil Engineering, Texas A\&M University, College Station, \\ TX 77843-3136, USA \\ ${ }^{2}$ Department of Civil and Environmental Engineering, University of Illinois at Urbana-Champaign, \\ IL 61801, USA
}

Correspondence should be addressed to Paolo Gardoni; gardoni@illinois.edu

Received 13 August 2012; Revised 4 December 2012; Accepted 18 December 2012

Academic Editor: Sadhan C. Jana

Copyright (C) 2013 Maryam Mardfekri et al. This is an open access article distributed under the Creative Commons Attribution License, which permits unrestricted use, distribution, and reproduction in any medium, provided the original work is properly cited.

\begin{abstract}
The nonlinear behavior of a laterally loaded monopile foundation is studied using the finite element method (FEM) to account for soil-pile interactions. Three-dimensional (3D) finite element modeling is a convenient and reliable approach to account for the continuity of the soil mass and the nonlinearity of the soil-pile interactions. Existing simple methods for predicting the deflection of laterally loaded single piles in sand and clay (e.g., beam on elastic foundation, $p-y$ method, and SALLOP) are assessed using linear and nonlinear finite element analyses. The results indicate that for the specific case considered here the $p$ - $y$ method provides a reasonable accuracy, in spite of its simplicity, in predicting the lateral deflection of single piles. A simplified linear finite element (FE) analysis of piles, often used in the literature, is also investigated and the influence of accounting for the pile diameter in the simplified linear FE model is evaluated. It is shown that modeling the pile as a line with beam-column elements results in a reduced contribution of the surrounding soil to the lateral stiffness of the pile and an increase of up to $200 \%$ in the predicted maximum lateral displacement of the pile head.
\end{abstract}

\section{Introduction}

Pile foundations are widely used to support laterally loaded structures especially offshore. The extensive growth of wind farms around the world has raised new concerns about the accuracy of the analysis and design methods for laterallyloaded large-diameter monopiles (the most popular foundation structure for offshore wind turbines).

Common methods for the analysis of laterally loaded single piles can be generally classified into two categories: (1) Winkler (elastic) foundation models and (2) continuous models accounting for the coupling of forces and displacements in the soil along the pile. In each category the analysis may be static (monotonic or cyclic loading) or dynamic. Also the behavior of the soil, pile, and soil-pile interaction may be considered as linear or nonlinear.

Winkler foundation models are popular because of their simplicity and reasonable accuracy. When the elastic stiffness of the foundation can be considered constant with depth one can even obtain simple closed form solutions for the pile head stiffness and flexibility [1]. The main difference between the different Winkler foundation models available is in the selection of the foundation stiffness coefficients. For dynamic problems Novak [2] has proposed the use of Winkler foundation coefficients based on Baranov's equations [3] for in plane and out of plane vibrations of a disk. The corresponding horizontal $k_{x}$ and rotational $k_{\varphi}$ springs per unit of length along the pile are functions of a dimensionless frequency $a_{0}=\Omega R / C_{s}$, where $\Omega=$ the frequency in radians/second, $R=$ the radius of the pile, and $C_{s}=$ the shear wave velocity of the soil. Unfortunately the horizontal term tends to zero at a zero frequency representing the static case. As a result it is common to use the values corresponding to a dimensionless frequency of 0.3 for smaller frequencies [1]. In that case, $k_{x}=4 G$ and $k_{\varphi}=2.6666 G R^{2}$, where $G=$ the shear modulus of the soil.

For nonlinear analyses the $p-y$ method is the most commonly used in this category. It employs an elastic beam 
column member to model the pile and nonlinear horizontal springs to represent the soil reactions. The $p-y$ curves describe the nonlinear behavior of the soil springs. They were developed first by Matlock [4] for soft clays under the water table. Reese and Welch [5] and Reese et al. [6] developed $p-y$ curves for hard clays subjected to monotonic and cyclic loading, above and under the water table, respectively. Analyzing the results of the full scale tests conducted by Reese et al. [6], Dewaikar et al. [7] presented a modified approach to construct $p-y$ curves in stiff clay. In another study Kim and Jeong [8] developed a framework based on 3D finite element analysis for determining a $p-y$ curve. The $p-y$ curves for sands were also developed by Reese et al. [9] for monotonic and cyclic loading. Briaud et al. [10] developed an alternative method to obtain the $p-y$ curves directly from pressuremeter tests. The method was reasonably accurate but complicated and time consuming, so Briaud [11] developed a simpler approach called "simple approach for lateral loads on piles" or SALLOP, using the pressuremeter limit pressure and the pressuremeter modulus.

A number of recent studies have been conducted to predict the behavior of laterally loaded piles in different soil conditions. Sanjaya Kumar et al. [12] used ABAQUS and the $p-y$ method to study the behavior of laterally loaded pile foundations in high marine clay with high potential to swell upon wetting and shrink upon drying. Suleiman et al. [13] conducted a test to measure the soil-pile interaction pressure for small diameter piles in loose sand that the results can be used in developing the soil force-displacement relationship (i.e., the soil reaction or the $p-y$ curve). An equivalent model for a laterally loaded linear pile-soil system was presented by Chioui and Chenu [14] using artificial lateral springs.

Continuous modeling of the pile and the surrounding soil are mostly done using finite element or boundary element models. Both methods can provide rigorous solutions accounting for soil-pile interaction under static and dynamic loading. For the linear case an accurate solution was proposed by Blaney et al. [15] using the consistent boundary matrix developed by Kausel [16] to reproduce the soil cavity occupied by the pile and adding then the pile enforcing compatibility of horizontal and vertical displacements between pile and soil along the pile. An extensive number of studies were carried out by Sanchez Salinero [1] comparing the results of this approach to those provided by a variety of other methods and proposing approximate formulas for the pile head stiffness. This approach is only valid however in the linear elastic range. The finite element method is particularly convenient when desiring to account for nonlinear effects including the nonlinear behavior of the soil and of the soil-pile interface.

A 3D nonlinear finite element analysis of a pile foundation in which both the soil and the pile are modeled with 3D finite elements can be quite expensive and time consuming, particularly when incorporating nonlinear behavior. As a result some investigators have used finite element models that represent the pile by an elastic beam column member without transverse dimensions (only the centroidal axis) and only the soil with 3D solid elements. This method takes into account the continuity of the soil mass and is easy to use for linear static and dynamic analysis. However, the most important limitation of this approach is that it does not take into account the dimension of the pile section.

The work presented in this paper is part of a broader research effort to assess the reliability of foundations for offshore wind turbines. These are normally single large diameter hollow piles. However many different methods have been used and investigated by previous researchers for analysis of laterally loaded piles, most of previous studies are focused on onshore pile foundations with diameters relatively smaller than those in the offshore industry. The first objective of this paper is to compare the results of different methods of analysis of laterally loaded piles and illustrate the possible variability of the results. A second objective is to investigate how the consideration of pile diameter affects the accuracy of simplified models. As a first step the models used for the analyses of these foundations are validated. Then the model selected is implemented in the computer program $A B A Q U S$ using $3 \mathrm{D}$ brick elements to discretize the soil around the pile and shell elements to model the hollow pile. The results obtained with this model for linear and nonlinear analyses are compared to those provided by a variety of other methods used in practice.

In the following, we first examine four different models used for linear analysis of single pile foundations and evaluate the influence of accounting for the pile diameter in the simplified linear FE analyses. In the next section, we improve the 3D finite element model by accounting for the nonlinearity of the soil and soil-pile interaction. Two common simplified nonlinear models are then assessed using this model for mono-piles in sand and clay.

\section{Linear Analyses}

Analyses considering linear soil behavior and perfect bonding between the pile and the surrounding soil are conducted first. The pile selected for the study is hollow with a diameter of $4 \mathrm{~m}$ and the properties listed in Table 1. Four different models are studied.

(1) The first model is a 3D finite element model of both the soil around the cavity occupied by the pile (solid elements) and for the pile, with shell elements for hollow piles and brick elements for solid piles (shown in Figure 1).

(2) The second, simpler, model reproduces the soil with solid elements filling the space without any cavity. The pile is represented by the centroidal axis of a $1 D$ beam column coinciding with the central axis of the soil model, enforcing only compatibility of horizontal displacements between the nodes of the pile and those of the soil along the axis.

(3) The third model is the one proposed by Blaney et al. [15] with the consistent boundary matrix with the radius of the cavity representing the soil and enforcing compatibility of both horizontal and vertical displacements between the soil and the pile along its sides.

(4) The fourth model is a beam on an elastic (Winkler) foundation with horizontal and rotational springs along the side of the pile. The constants selected for the foundation are $k_{x}=4 G$ and $k_{\varphi}=2.6666 G R^{2}$. 
TABle 1: Properties of the pile.

\begin{tabular}{lcc}
\hline Parameter & Symbol & Value \\
\hline Penetration depth $(\mathrm{m})$ & $L$ & 21.0 \\
Diameter $(\mathrm{m})$ & $D$ & 4.00 \\
Wall thickness $(\mathrm{m})$ & $t$ & 0.05 \\
Modulus of elasticity $(\mathrm{kPa})$ & $E_{p}$ & $2.0 E 8$ \\
Unit weight $\left(\mathrm{kN} / \mathrm{m}^{3}\right)$ & $\gamma_{p}$ & 87.00 \\
Poisson ratio & $v_{p}$ & 0.30 \\
\hline
\end{tabular}

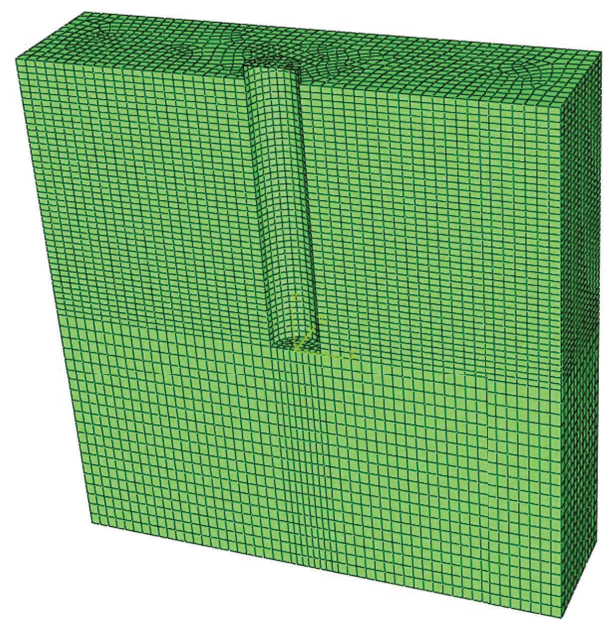

Figure 1: 3D finite element model of the pile foundation.

The pile is subjected at the head to a vertical load of $5,000 \mathrm{kN}$, a horizontal load of $2,503 \mathrm{kN}$, and a moment of $84,983 \mathrm{kNm}$. These are values obtained considering the extreme forces on an offshore wind turbine. For the linear analyses the soil is assumed to have a Young's modulus $E_{s}=$ $50,000 \mathrm{kPa}$, a Poisson's ratio $v_{s}=0.3$, and a unit weight $\gamma_{s}=20 \mathrm{kN} / \mathrm{m}^{3}$.

The predicted deflections at the pile head by the four models are $20.9 \mathrm{~mm}$ for the 3D FE pile model, $68.3 \mathrm{~mm}$ for the 1D FE pile model, $20.5 \mathrm{~mm}$ for the consistent boundary matrix and $24.3 \mathrm{~mm}$ for the Winkler foundation. The deformation of the soil with the 3D finite element model is shown in Figure 2 while Figure 3 shows the corresponding deformations with the 1D model of the pile. The results, obtained using the 3D finite element model, are in good agreement with the approach that employs consistent boundary matrix (less than $2 \%$ off). The agreement with the results of the Winkler foundation is not quite as good but still acceptable (about $20 \%$ off). The model without the cavity and with the pile as a 1D linear element yields deflections that are $200 \%$ too large.

To understand better the reasons for this large discrepancy it was decided to conduct studies for other pile sizes. Clearly the results of the 1D model are only a function of the soil properties and of the product $E I$ of the Young's modulus of the pile by the moment of inertia of the cross section but not explicitly of the pile diameter. For a hollow pile the moment of inertia is not uniquely related to the diameter and therefore in this case the actual size of the cavity has no effect

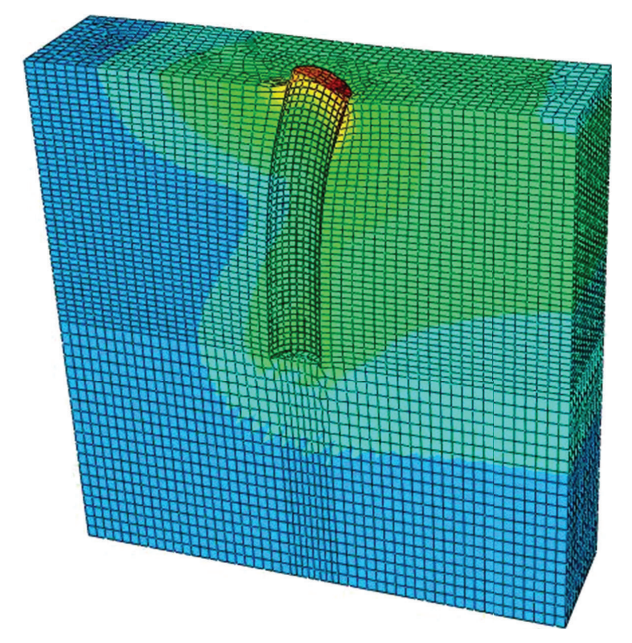

FIGURE 2: Deformation of the soil with the 3D model of the pile.

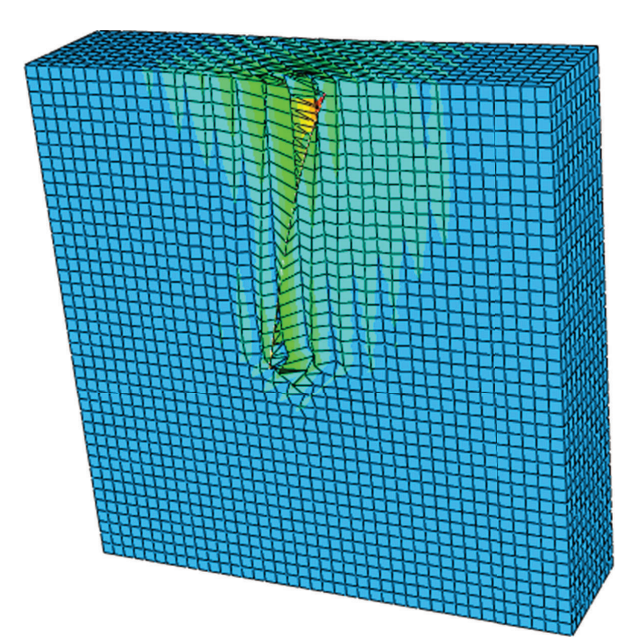

Figure 3: Deformation of the soil with the 1D model of the pile.

on the results of the model if the moment of inertia is kept constant. This would also be the case for a Winkler foundation model with only horizontal springs.

Table 2 shows the results of the four models for hollow piles with the same EI value of $2.421 E+8 \mathrm{kN}-\mathrm{m}^{2}$, but diameters of 1,2 , and $4 \mathrm{~m}$. The agreement between the 3D finite element model and the boundary matrix method is good in all three cases (about 3\% off in average). As expected the results for the $1 \mathrm{D}$ pile model do not change. The results for the Winkler model vary slightly because of the rotational springs but the variation is still very small and the accuracy deteriorates as the diameter of the pile decreases. To see when the results of the 1D model would become similar to those of the more accurate solutions the boundary matrix model was run for a larger number of diameters going down to $0.02 \mathrm{~m}$. Figure 4 shows the variation of the head displacement with the pile diameter in semi-log scale. The deflection predicted by the boundary matrix model for a pile with a diameter of $0.02 \mathrm{~m}$ is $68.5 \mathrm{~mm}$ now in good agreement with the prediction of the $1 \mathrm{D}$ model. It is interesting to observe that the variation 
TABLE 2: Variation of pile head displacement versus pile diameter in different linear analysis methods with constant EI for the pile.

\begin{tabular}{lcccc}
\hline Pile diameter $(\mathrm{m})$ & & & Pile head deflection $(\mathrm{mm})$ \\
& 3D pile FEM & 1D pile FEM & Consistent boundary matrix & Winkler foundation \\
\hline 1.00 & 32.5 & $68.3(110 \%)$ & $34.0(5 \%)$ & $25.2(23 \%)$ \\
2.00 & 27.6 & $68.3(148 \%)$ & $27.5(1 \%)$ & $25.0(10 \%)$ \\
4.00 & 20.9 & $68.3(227 \%)$ & $20.5(2 \%)$ & $24.3(17 \%)$ \\
\hline
\end{tabular}

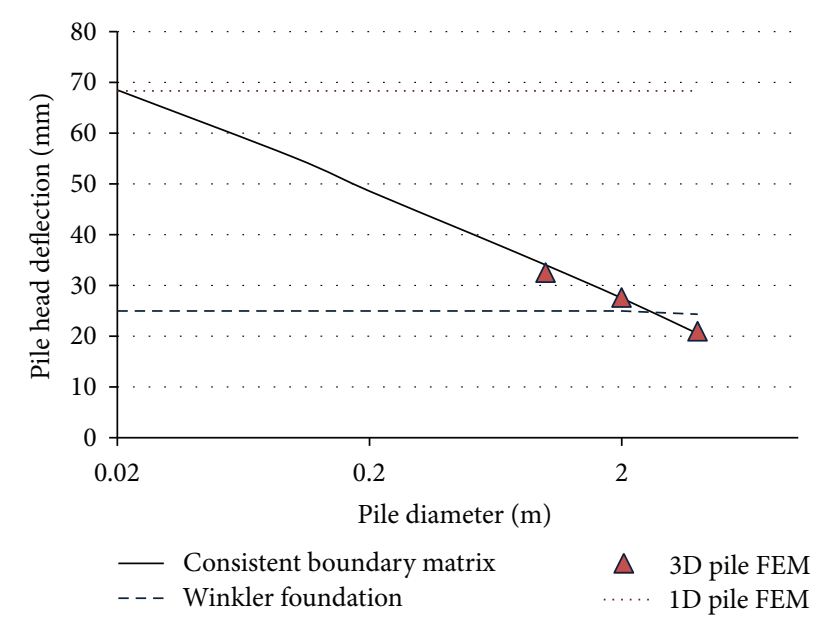

FIGURE 4: Variation of pile head displacement versus pile diameter in linear analyses with constant $E I$ for the pile.

of the displacement for this hollow pile is approximately inversely proportional to the radius to the power 0.26 . It is noteworthy that while clearly the piles with very small diameter and large value of EI are unrealistic, it is desired to cover a wide range of values of the diameter to see more clearly the trend. It must also be remembered that when using a $1 \mathrm{D}$ beam-column to represent the pile with a finite element soil mesh that does not include a cylindrical cavity, one is assuming a zero diameter that is not just unrealistic but physically impossible.

\section{Nonlinear Analyses}

Three different models are used to conduct nonlinear analyses as follows.

(1) The 3D finite element model of the previous runs. In this case however the soil and the soil-pile interface are nonlinear. The finite element model, using ABAQUS, has the capability of taking into account the initial state of stresses in the soil mass. The initial conditions of stress are applied before the pile is installed and as a first step the effective body forces are calculated to account for geostatic equilibrium. The extreme static loads due to the performance of the turbine and wave and wind loading are applied then.

A $22 \mathrm{~m}$ long pile with a diameter of $4 \mathrm{~m}$ is modeled as a steel pipe using 4-node quadrilateral shell elements with reduced integration. A $1 \mathrm{~m}$ long segment of the pile is considered to be above ground level to avoid the soil going over the pile. Linear elastic behavior is assumed for the pile.
TABLE 3: Elastic-plastic properties of soil.

\begin{tabular}{lccc}
\hline \multirow{2}{*}{ Parameter } & \multirow{2}{*}{ Symbol } & \multicolumn{2}{c}{ Value } \\
& & Sand & Clay \\
\hline Modulus of elasticity $(\mathrm{kPa})$ & $E_{s}$ & $5.0 E 4$ & $4.5 E 4$ \\
Unit weight $\left(\mathrm{kN} / \mathrm{m}^{3}\right)$ & $\gamma_{s}$ & 20.00 & 20.00 \\
Poisson ratio & $v_{s}$ & 0.30 & 0.30 \\
Angle of internal friction $\left({ }^{\circ}\right)$ & $\phi$ & $€ 40.0$ & - \\
Undrained shear strength $(\mathrm{kPa})$ & $S_{u}$ & - & 150.0 \\
\hline
\end{tabular}

For an actual soil profile it would be necessary to select the most appropriate nonlinear constitutive model and to determine the values of the required parameters defining the model from laboratory tests. For the purposes of this work and considering two hypothetical soils, a sand and a clay, a very simple Mohr Coulomb model, as implemented in the program ABAQUS, is used with the properties presented in Table 3. The finite element mesh of the $40 \mathrm{~m} \times 10 \mathrm{~m} \times 41 \mathrm{~m}$ soil mass is generated using isoparametric brick elements with reduced integration for the soil.

The nonlinear behavior of the soil-pile contact is modeled using "contact pair" in ABAQUS. Tangential movement between the two parts, pile and surrounding soil, is allowed with a friction coefficient of 0.67 . In the radial direction, a "no separation" contact behavior is assumed. The pile outer surface is chosen as the "master surface" and the surface of the soil mass which is in contact with the pile is considered to be the "slave surface." The "small sliding" tracking approach is employed for the contact of the two bodies assuming that even if the two bodies undergo large motions, there is relatively little sliding of one surface along the other. An elastic-plastic Coulomb model is also used to describe the nonlinear behavior of the soil-pile contact. Figure 5 shows the deformation of soil with 3D nonlinear finite element model of pile foundation.

(2) A model using the $p-y$ curves is implemented specifically for this work. As indicated in the introduction section the $p-y$ curves were originally proposed by Matlock [4] for soft clays under the water table and models for hard clays and sands were shortly after introduced by Reese et al. [6]. In this work the sand and the hard clay model are used. The clay model requires the specification of a parameter $\varepsilon_{50}$ that has to be determined from experiments. Since the soil considered was not a real one on which experiments could be performed a value of 0.005 , as recommended by Reese et al. [6], is used. In the linear elastic range, for very small displacements, the initial stiffness of the springs representing the $p-y$ curves normally varies with depth. In this case 


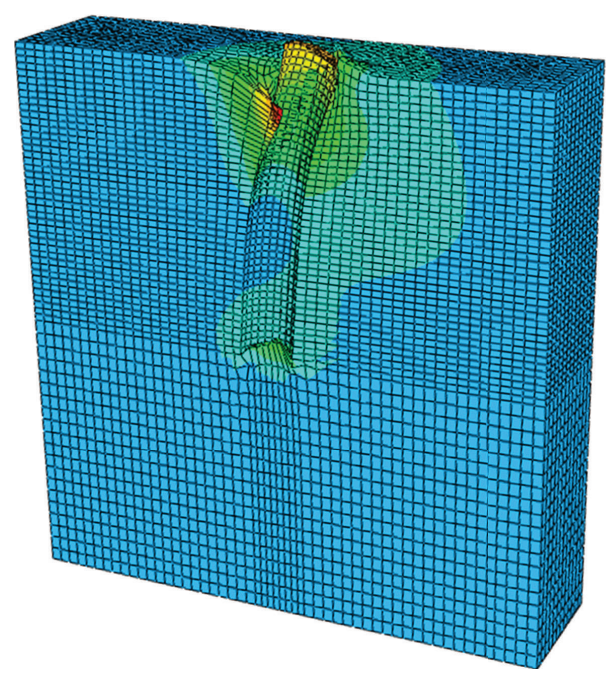

FIGURE 5: Deformed mesh of the pile foundation in 3D nonlinear analysis.

however, to be consistent with the finite element model the initial stiffness value is considered to be constant with the depth and equal to $4 G$ as for the linear analyses with the Winkler foundation. Since the $p-y$ curves are in fact a form of the Winkler foundation model with only horizontal springs the solution in the elastic range would be only a function of the $E I$ of the pile and independent of the diameter for a given moment of inertia. The nonlinear variation of the stiffness is on the other hand affected by the pile diameter. It should also be noticed that with the $p-y$ method there are nonlinear springs attached to the side of the pile but not at the bottom. One must decide therefore whether the pile tip is free, hinged or fixed. For long piles the difference between these three cases when considering the pile head displacement is negligible. However, in the present case the parameter $l_{0}=\left(4 E_{p} I_{p} / K\right)^{1 / 4}$, with $E_{p}=$ modulus of elasticity for the pile (kPa); $I_{p}=$ moment of inertia for the pile $(\mathrm{m} 4)$; and $K=$ soil-spring constant $(\mathrm{kPa})$, which is the ratio of the soil resistance $P(\mathrm{kN} / \mathrm{m})$ at a depth $z$ to the horizontal pile displacement $y(\mathrm{~m})$ at the same depth, is of the order of $10 \mathrm{~m}$ so the displacements for a hinged tip may be $25 \%$ smaller than for a free tip. For a linear analysis the assumption of a hinged tip, where the displacement of the pile tip is assumed to be constrained and equal to that of the soil mass at the bottom, while the rotation is allowed freely, may be more realistic but for the nonlinear one it is considered that the free end, where both the tip displacement and rotation are allowed, would be more appropriate. For the sake of comparison and to see the effects of such assumption the results are presented for both boundary conditions.

(3) A model implementing the simple approach for lateral loads on piles (SALLOP) proposed by Briaud [11]. It is a semitheoretical or semiempirical method in which the framework is theoretical but the factors in the theoretical equations are adjusted by comparison to some full-scale load tests. SALLOP uses two different theoretical solutions for infinitely long (flexible) piles and for short rigid piles in a
Winkler uniform soil. Defining a transfer length $l_{0}$ that is the typical parameter associated with the solution of a beam on elastic foundation, as done earlier, the pile head displacement $y_{0}$ for long flexible piles $\left(L \geq 3 l_{0}\right)$ under a combined loading of a horizontal force and a moment at its head is [17]

$$
y_{0}=\frac{2 H_{0}}{l_{0} K}+\frac{2 M_{0}}{l_{0}^{2} K},
$$

where $H_{0}=$ horizontal force applied at the pile head $(\mathrm{kN})$, $M_{0}=$ moment applied at the pile head $(\mathrm{kNm})$, and the soil-spring constant $K$ is defined empirically by optimizing the comparison between the predicted deflection and the measured deflections.

Similarly, the pile head displacement for short rigid piles $\left(L \leq l_{0}\right)$ is Should we change

$$
y_{0}=\frac{2\left(2 H_{0} L+3 M_{0}\right)}{K L^{2}} .
$$

For the SALLOP calculations a linear interpolation between two values will be used if the pile length is between $l_{0}$ and $3 l_{0}$. More details on SALLOP are presented at Briaud [17].

For the pile with a diameter of $4 \mathrm{~m}$, the 3D finite element model predicts a displacement of $40 \mathrm{~mm}$ in sand and $25.1 \mathrm{~mm}$ in clay. The corresponding results with the $p-y$ curves are $38.2 \mathrm{~mm}$ and $37.5 \mathrm{~mm}$ with a free tip $(28.5 \mathrm{~mm}$ with a hinge at the bottom); with the SALLOP method 36.0 and $45 \mathrm{~mm}$. The three methods provide results in good agreement for the sand but there are larger differences for the clay particularly for the SALLOP approach and with a free tip for the $p-y$ curves.

The effect of the pile diameter with a constant value of the $E I$ of the pile was again investigated for the nonlinear case. Table 4 and Figure 6 present the results of the three methods for diameters of 1,2 , and $4 \mathrm{~m}$. Again since the SALLOP method is based purely on a Winkler foundation with horizontal springs the results are independent of the diameter for a fixed $E I$. The $p-y$ curves give results that vary with the diameter but less significantly than the 3D solution. It is interesting to notice that for the sand the best agreement is obtained for a diameter of $4 \mathrm{~m}$. For the $1 \mathrm{~m}$ diameter the prediction of the SALLOP method would be about $40 \%$ of the FEM result; with the $p-y$ curve it would be about $62 \%$. For the clay on the other hand the best agreement between the three methods is obtained for the diameter of $1 \mathrm{~m}$ (almost exactly the same results), whereas the discrepancy increases as the diameter increases. The prediction with the SALLOP method is about $80 \%$ too large whereas that with the $p$ $y$ curves assuming a free tip is about $50 \%$ off for the $4 \mathrm{~m}$ diameter.

It seems also that given the lack of a spring acting on the bottom face of the pile in the $p-y$ model, for the larger diameter pile the assumption of a hinged tip might be more realistic whereas for the smaller diameters it is better to consider a free tip. Considering the fact that the characteristics of the soils are not actually determined from laboratory tests but some of the parameters are chosen purely as logical values, and that a very simple nonlinear soil model was used, finding an exact agreement between the three methods would have been surprising. The fact that they provide results with the 
TABLE 4: Variation of pile head displacement versus pile diameter in different nonlinear analysis methods with constant $E I$ for the pile.

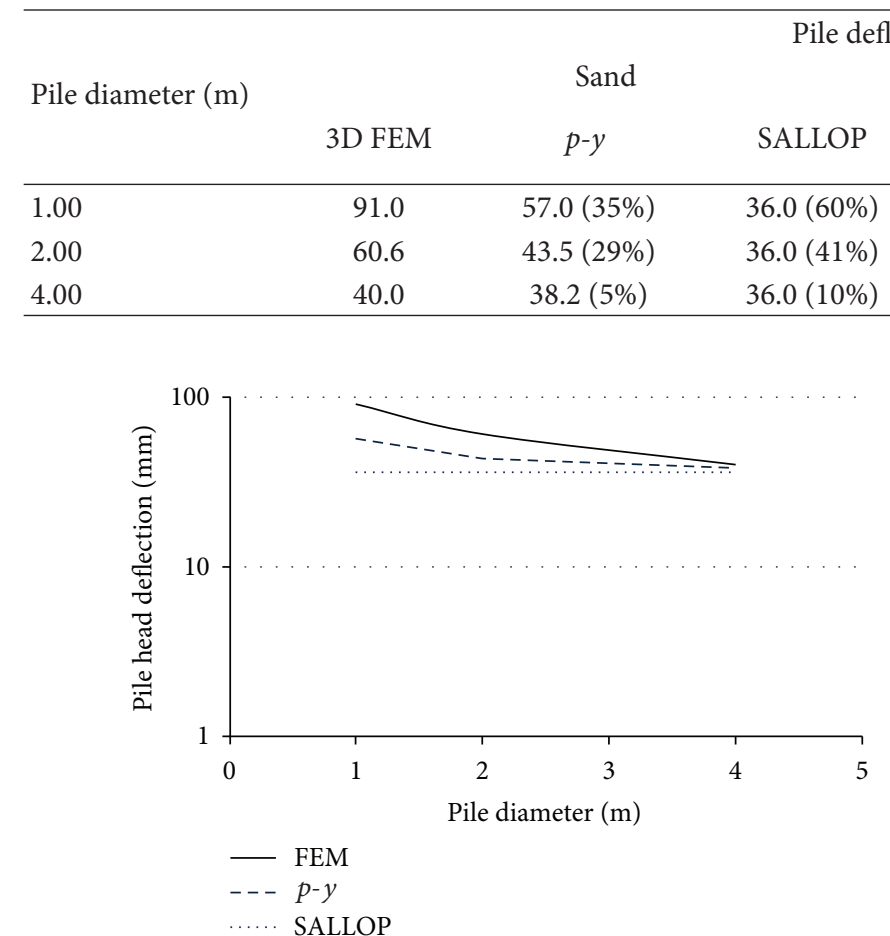

(a)

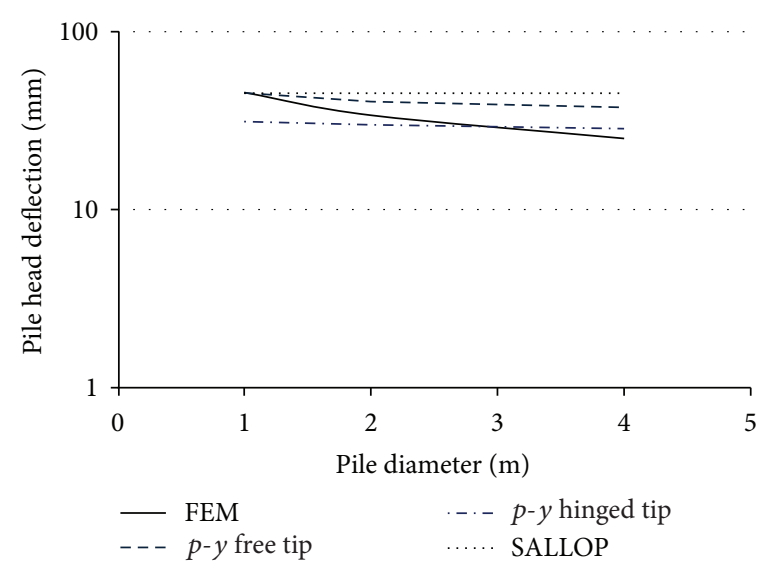

(b)

FIGURE 6: Variation of pile head displacement versus pile diameter in nonlinear analyses for (a) sand and (b) clay with constant EI for the pile.

same order of magnitude for the range of pile diameters considered is encouraging. On the other hand it is important to notice the effect of the pile diameter on the foundation stiffness beyond the value of the EI, something that would occur irrespective of the constitutive model used. Obtaining a very good agreement for a given pile diameter with a more refined selection of the nonlinear soil model and of the soil parameters will not guarantee similar accuracy for other values of the diameter and the same soil.

\section{Summary and Conclusions}

This study for the first time provides a comprehensive comparison of common techniques for analysis of laterally loaded single piles in different soil types and for a wide range of pile dimensions. The effect of the pile diameter on its lateral behavior in the linear elastic range was studied using various analysis procedures assuming a constant pile stiffness (EI) and different pile diameters for hollow piles: a 3D ABAQUS finite element model, a model with the soil reproduced with $3 \mathrm{D}$ elements but the pile represented by a line, a model using a consistent boundary matrix and a Winkler foundation model. The results show that the pile head lateral deflection is not only a function of EI but also of the pile diameter. It decreases considerably as the pile diameter increases while $E I$ is maintained constant. Modeling a pile as a $1 D$ line with beam-column elements, as done sometimes in the literature, results in a smaller contribution of the surrounding soil to the lateral stiffness of the pile and an increase of up to $200 \%$ in the maximum displacement of the pile head.

Nonlinear analyses were next conducted using the three dimensional finite element models of the soil and pile employing ABAQUS for a sand and a clay. The static (monotonic) calculations were conducted for an extreme lateral load and bending moment. A Mohr-Coulomb constitutive model was used for the generic soils. The nonlinear contact between the pile and the soil were accounted for using some of the tools available in ABAQUS. The results were compared to those provided by the use of $p-y$ curves for sand and hard clay and with the SALLOP method suggested by Briaud [11]. Both the $p-y$ model for sand and the SALLOP method provide reasonable answers for the pile with a diameter of $4 \mathrm{~m}$ but the accuracy deteriorates for smaller diameters, particularly for the SALLOP method where the results are independent of the diameter for a fixed value of EI. For the clay the $p-y$ curves assuming a free tip and the SALLOP predictions are good for the smaller diameter pile (diameter of $1 \mathrm{~m}$ ) but deteriorate for larger diameters. It appears that for these cases with the $p-y$ method the assumption of a pile hinged at the bottom would provide better results.

The study conducted uses the 3D nonlinear finite element model as an accurate model for the pile sizes of interest in relation to the foundations of offshore wind turbines to assess other, simpler models. It indicates that when using common 
simple models and particularly if the pile is modeled as a line, neglecting the size of the soil cavity, the results may be inaccurate.

\section{References}

[1] I. Sanchez Salinero, "Static and dynamic stiffnesses of single piles," Geotechnical Engineering Report GR82-31, The University of Texas at Austin, 1982.

[2] M. Novak, "Dynamic stiffness and damping of piles," Canadian Geotechnical Journal, vol. 11, no. 5, pp. 574-698, 1975.

[3] V. A. Baranov, "On the calculation of excited vibrations of an embedded foundation," Voprosy Dynamiki Prochnocti, vol. 14, pp. 195-209, 1967 (Russian).

[4] H. Matlock, "Correlations for design of laterally loaded piles in soft clay," in Proceedings of the 2nd Annual Offshore Technology Conference, vol. 1, pp. 577-588, 1970, Paper 1204.

[5] L. C. Reese and R. C. Welch, "Lateral loading of deep foundations in stiff clay," Journal of the Geotechnical Engineering Division, vol. 101, no. 7, pp. 633-649, 1975.

[6] L. C. Reese, W. R. Cox, and F. D. Koop, "Field testing and analysis of laterally loaded pilein stiff clay," in Proceedings of the 7th Annual Offshore Technology Conference, vol. 2, pp. 671-690, 1975, Paper 2312.

[7] D. M. Dewaikar, R. S. Salimath, and V. A. Sawant, "A modified P-Y curve for the analysis of a laterally loaded pile in stiff clay," Australian Geomechanics Journal, vol. 44, no. 3, pp. 91-100, 2009.

[8] Y. Kim and S. Jeong, "Analysis of soil resistance on laterally loaded piles based on 3D soil-pile interaction," Computers and Geotechnics, vol. 38, no. 2, pp. 248-257, 2011.

[9] L. C. Reese, W. R. Cox, and F. D. Koop, "Analysis of laterally loaded piles in sand," in Proceedings of the 6th Annual Offshore Technology Conference, vol. 2, pp. 473-483, 1974, Paper 2080.

[10] J. L. Briaud, T. D. Smith, and L. M. Tucker, "A pressuremeter method for laterally loaded piles," in Proceedings of the 11th International Conference on Soil Mechanics and Foundation Engineering, vol. 3, pp. 1353-1356, A.A. Balkema, Rotterdam, The Netherlands, 1985.

[11] J. L. Briaud, "SALLOP: simple approach for lateral loads on piles," Journal of Geotechnical and Geoenvironmental Engineering, vol. 123, no. 10, pp. 958-964, 1997.

[12] V. Sanjaya Kumar, K. G. Sharma, and A. Varadarajan, "Behaviour of a laterally loaded pile," in Proceedings of the 10th International Symposium on Numerical Models in Geomechanics (NUMOG '07), pp. 447-452, April 2007.

[13] M. T. Suleiman, A. Raich, T. W. Polson, W. J. Kingston, and M. Roth, "Measured soil-pile interaction pressures for smalldiameter laterally loaded pile in loose sand," in GeoFlorida: Advances in Analysis, Modeling and Design Conference, pp. 1498-1506, February 2010, Geotechnical Special Publication, Paper 199.

[14] J. S. Chioui and C. H. Chenu, "Exact equivalent model for a laterally-loaded linear pile-soil system," Soils and Foundations, vol. 47, no. 6, pp. 1053-1061, 2007.

[15] G. W. Blaney, E. Kausel, and J. M. Roesset, "Dynamic stiffness of piles," in Proceedings of the 2nd International Conference on Numerical Methods in Geomechanics, pp. 1001-1012, 1976.

[16] E. Kausel, "Forced vibrations of circular foundations on layered media," Research Report R 74-11, Civil Engineering Department, MIT, 1974.
[17] J. L. Briaud, The Pressuremeter, A. A. Balkema, Rotterdam, The Netherlands, 1992. 

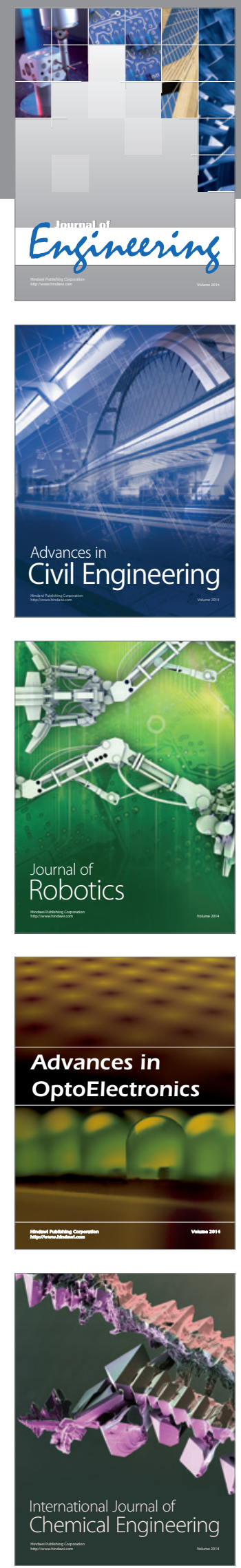

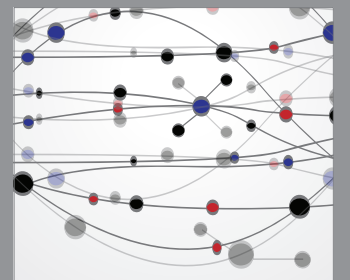

The Scientific World Journal
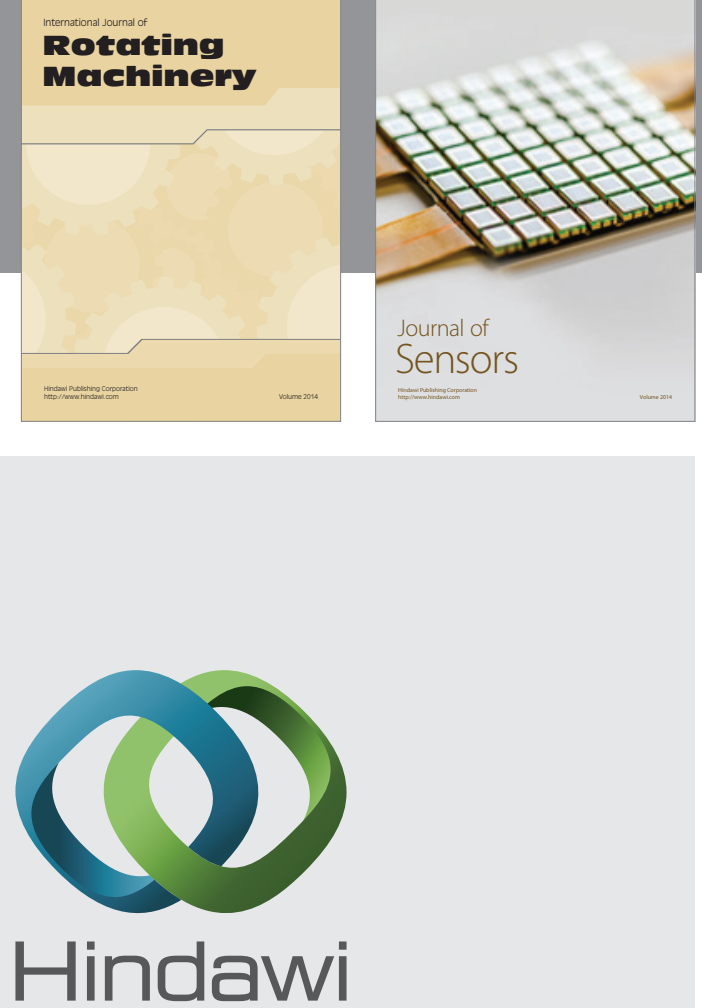

Submit your manuscripts at http://www.hindawi.com
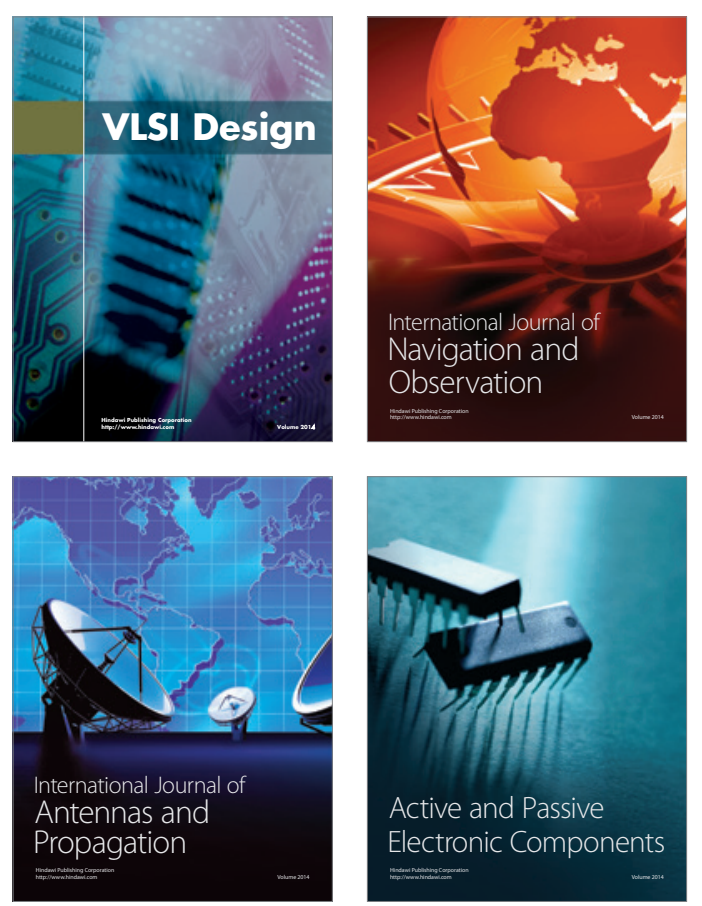
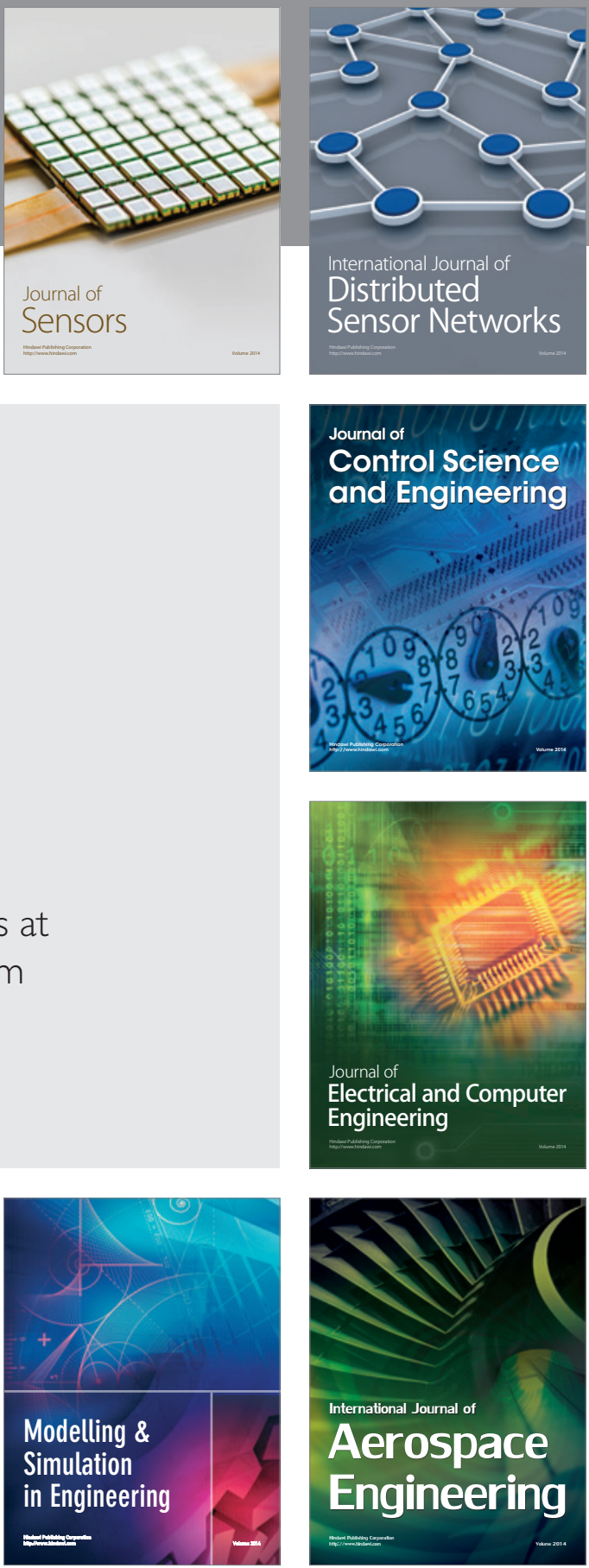

Journal of

Control Science

and Engineering
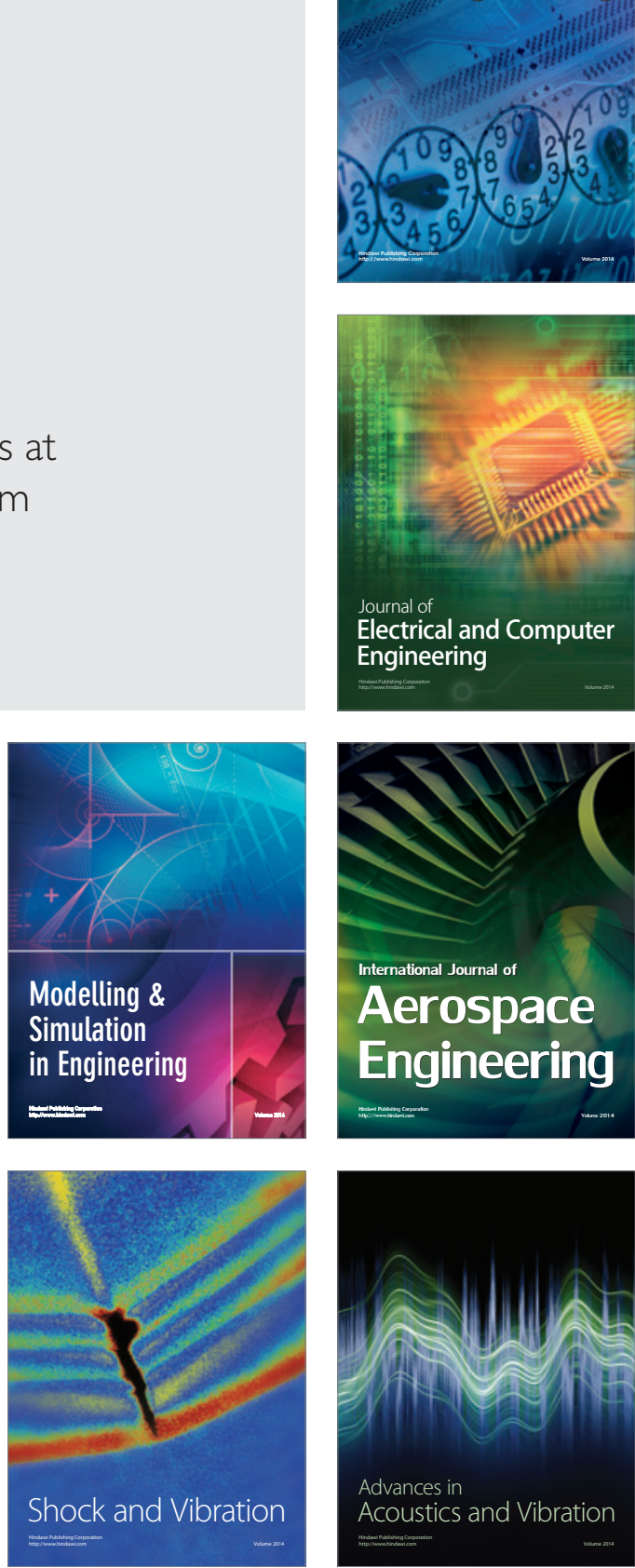